\title{
EGF Vaccine EGF-PTI
}

National Cancer Institute

\section{Source}

National Cancer Institute. EGF Vaccine EGF-PTI. NCI Thesaurus. Code C163023.

A cancer vaccine containing epidermal growth factor (EGF), with immunomodulating and antineoplastic activities. Upon administration of the EGF vaccine EGF-PTI, EGF induces an immune response against EGFR, which results in the formation of anti-EGF-specific neutralizing antibodies. This causes binding of the anti-EGF antibodies to endogenous EGF, reduces levels of circulating EGF and prevents the binding of EGF to its receptor EGFR. This prevents EGF/EGFR pathway activation and may result in an inhibition of proliferation in EGFR-overexpressing tumor cells. EGF/EGFR-mediated signaling is overactivated in certain cancer types and drives tumor cell proliferation and progression. 